\title{
The COVID-19 Beta Effect, An Empirical Study in Palestine
}

\author{
Dr. Adnan A.A Qubbaja \\ Tasnim M.I. Odeh \\ Palestine Ahliya University -Bethlehem
}

Head of Financial and Banking Science Department, Palestine Ahliya University -Bethlehem

\begin{abstract}
This study attempts to investigate the impact of COVID-19 pandemic on systematic risks measured by beta in Palestine Exchange during the period from January, 2018, to March, 2021, using Wilcoxon statistical test tool. The study consists of 12 Palestinian public companies listed in the PEX, The 12 companies' betas were estimated before and after the occurrence of pandemic, 20 March 2020, The results show that there is no significant difference between the systematic risk $(\beta)$ of companies before and after COVID-19
\end{abstract}

Keywords: COVID-19,Beta, Palestine Exchange, Systematic Risk

DOI: $10.7176 /$ RJFA/12-22-04

Publication date: November $30^{\text {th }} 2021$

\section{Introduction}

During December 2019, the world became aware of a new global threat called coronavirus, which the World Health Organization (WHO) declared a COVID-19 a pandemic on March 11, 2020. COVID-19 pandemic changed the lives of millions of people around the world as reflected in the number of people infected and dying (Phan \& Narayan, 2020). Accordingly, economic logic indicates that the bad news in the stock markets may affect the process of capital accumulation in the financial sector; therefore, if this news increases the risks in investment operations, the potential effect will be to reduce the value and number of transactions in the stock market and then the stock returns, especially when the news contains risks on a global scale (Ashraf, 2020).

The COVID-19 pandemic has affected global financial markets. Continuous revisions of economic growth forecasts and heightened risk aversion, combined with extreme uncertainty about the future development of the pandemic, have resulted in extreme volatility in stock markets and other markets for risky assets. At the end of February 2020, the financial markets entered a phase of risk aversion with significantly increasing volatility across the markets. Stock markets began to decline rapidly, losing about $30 \%$ of its market value within weeks, with the sell-off speeding up faster than the global financial crisis of 2008. Overall, stock markets have responded negatively to COVID-19 pandemic and have recovered somewhat after the bailout program was announced (Rahman, et al. 2021). Therefore, assessing the impact of the COVID-19 pandemic on stock markets is imperative.

Betas have decreased for the Technology, Health Care, and Pharmaceutical sectors. While certain technology stocks, especially those like Zoom in the "work-from-home" category, might have been viewed as speculative growth stocks before the pandemic, they are now behaving more like recessionary plays. To highlight an extreme case, Zoom's stock went from a pre-pandemic beta greater than 1 to a negative beta. The negative Equity beta means bad news for the stock market is good news for Zoom, as the company's "revenues presumably expand when more people work remotely." ( CFA,2020)

In Palestine MAS's economic monitor identifies sectors that are expected to be most and least affected by the COVID-19 pandemic. The most affected sectors include mining and stone cutting, trade, transport and storage as well as services in general. The least affected sectors on the other hand include healthcare, education, food and medical supplies and manufacturing, amongst others. When discussing unemployment, the monitor differentiates between three types of workers, according to their level of exposure to unemployment: temporarily unemployed workers who will go back to their jobs after the pandemic, workers laid off because of the pandemic, and jobseekers. The analysis focuses on those expected to be laid off, with the majority of them expected to be irregular wage workers. According to 2017 data, the latter constitute 17\% of workers, and are concentrated in low skilled jobs and elementary occupations. (International Labour Organization, 2020).

The Palestine Stock Exchange recorded a loss of USD 34,360 (net), a decrease of $110 \%$ compared with profits for the same period during the previous year, 2019. 4 6. During the first half of 2020, the total value of market transactions recorded a decrease of $69 \%$ compared to the same period in 2019. The net profits of Palestinian banks listed on the Palestine Stock Exchange declined by 2.19\% during Q1 2020

However, .( Abd-Alla, 2020) found that COVID-19 crisis does not affect stock returns for the portfolios consisting of stocks with high and medium $\mathrm{B} / \mathrm{M}$ ratio and the portfolios consisting of small stocks

This study contributes to the existing literature by presenting an attempt to investigate the impact of COVID19 pandemic on systematic risks measured by beta in Palestine Stock Exchange during the period from January, 2018, to March, 2021, using Wilcoxon statistical test tool.. 


\section{Literature Review:}

The coronavirus (COVID-19) as a global pandemic, its characteristics are that it has an unknown etiology, no targeted drugs, and a lack of sufficient experience in treatment methods. All countries are responding to this pandemic, which is causing great losses to the global economy and financial markets (Aslam et al., 2020). Therefore, studying the impact of the pandemic on the economy is a hot topic that has recently piqued researchers interest (Liu et al., 2020).

Most empirical studies confirmed the negative response of the stock market indices to the spread of the COVID-19 pandemic (Cao et al., 2020). Moreover,( Khan et al.,2020) showed that the growth rate of weekly new cases of COVID-19 negatively predicts the returns in stock markets of sixteen countries.

(Bash ,2020) analyses the Cumulative Average Abnormal Return of 30 countries. The results show that there is negative impact of Covid-19 on the stock market returns. The stock markets in these countries reacted negatively after first case if the Covid-19 was reported. countries. Results revealed that there was significant negative impact on 11 global share market indices.

(Kulal , 2020) empirically identifies Covid-19 impact on Indian Stock Exchange using data from January 2, 2020 to January 22, 2020 of the NSE (National Stock Exchange). The result showed short-term downturn in stock market returns, and that there is significant effect of Covid-19 on the Indian stock market.

(Khanthavit ,2020) estimated the COVID-19 effects for the Chinese stock market returns compared to 10 markets - five most affected countries (United States, India, Brazil, Russia, and France) and five best recovering countries (Hong Kong, Australia, Singapore, Thailand, and South Korea). The study concluded that the COVID19-induced returns replace the pre-COVID-19 normal returns; it is also negatively auto-correlated and highly volatile. The COVID-19-induced returns are new normal returns in the COVID-19 period.

(Khanthavit, A. (2020). Measuring COVID-19 Effects on World and National Stock Market Returns. Journal of Asian Finance, Economics and Business 8(2), 1-13. relative to betas estimated prior to COVID-19 regardless of the sampling frequency used. For example, 53\% to $60 \%$ of the companies listed in the S\&P 500 Index experienced an increase in beta when we incorporated the COVID-19 era data into the sample period. Conversely, $40 \%$ to $54 \%$ of betas decreased or stayed the same.

Yousef (2020), which investigates the impact of the (COVID-19) on stock market volatility for the major G7 stock market indices, i.e., the S\&P500 index for the USA, the FTSE100 index for the UK, the S\&P/TSX index for Canada, the DAX index for Germany, the CAC40 index for France, the FTSE MIB Index for Italy, and the Nikkei 225 index for Japan. The results reveal that the COVID-19 has increased stock market volatility in all countries.

(Sharma,2020) examined whether the COVID-19 pandemic has changed the common denominators of volatility in five developed Asian economies, Hong Kong, Japan, Russia, Singapore, and South Korea. The study found that commonalities in volatility during the COVID-19 period more pronounced in the case of Singapore compared to the other four economies.

\section{3- Problem Statement:}

Market movements during the coronavirus pandemic have shifted the risk characteristics of many stocks. Technology and Health Care, have behaved like "safety plays" during the pandemic, while defensive stocks, such as Utilities and Real Estate, have declined notably. In an exhibit titled "Shifting Risk", This study attempts to investigate the impact of COVID-19 pandemic on systematic risks measured by beta in Palestine Stock Exchange during the period from January, 2018, to March, 2021, using Wilcoxon statistical test tool.

\section{4- Objective of the Study :}

The aim of this study is to examine the impact of COVID-19 Pandemic on systematic risks measured by beta in Palestine Stock Exchange during the period from January, 2018, to March, 2021.

\section{5- Research Questions:}

The research questions that are set to this paper include to What is the impact of COVID-19 Pandemic on systematic risks measured by beta in Palestine Stock Exchange?

\section{6- Research Hypothesis:}

In order to direct the direct flow of this study, the following hypothesis were formulated in line with objectives of the study

H0: There is no significant difference between systematic risks measured by beta in Palestine Stock Exchange before and after the ongoing COVID-19 pandemic.

\section{7- Methodology :}

The study examines the ability of beta factor to reflect the systematic risks resulted from the COVID-19 crisis and examines the impact of COVID-19 crisis on stock returns in Palestine Stock Exchange, Stock beta factors will be 
calculated before and after the official announcement of the first confirmed case of COVID-19 by the Palestinian Ministry of Health. Wilcoxon signed-rank will be used to compare stocks beta before and after the COVID-19 crisis.

\section{DATA ANALYSIS AND DISCUSSION:}

\subsection{Descriptive Analysis}

This research data analysis included descriptive statistics and analysis of different tests on public companies' in Palestine Stock Exchange before and after COVID-19 pandemic. First, a data normality test was conducted to determine which statistical tests would be used in the difference test.

The normality test results show that the research data were not normally distributed, so the data could not be tested using a parametric statistical test. Therefore, a non-parametric statistical test was done using the Wilcoxon signed-rank.

The study consists of 12 Palestinian public companies listed in the PEX, The 12 companies' betas were estimated before and after the occurrence of pandemic, 20 March 2020. Based on the Wilcoxon signed-rank test (Table 1), the data showed 7 negative ranks for stock Beta, 5 positive ranks for stock Beta, and 0 ties.

\subsection{Hypothesis Tests :}

As the significance level is more than 0.05 , there is no significant difference between the systematic risk $(\beta)$ of companies before and after COVID-19 The following table 2, showed the result of the test about the systematic risk before and after the C OVID-19.

Table 1 : Wilcoxon signed-rank test for base and post-test scores - paired samples test Ranks

\begin{tabular}{|ll|r|r|r|}
\hline & & $\mathrm{N}$ & Mean Rank & \multicolumn{1}{c|}{ Sum of Ranks } \\
\hline & Negative Ranks & $7^{\mathrm{a}}$ & 7.43 & 52.00 \\
BETA_AFTER & Positive Ranks & $5^{\mathrm{b}}$ & 5.20 & 26.00 \\
BETA_BEFORE & Ties & $0^{\mathrm{c}}$ & & \\
& Total & 12 & \\
\hline
\end{tabular}
a. BETA AFTER $<$ BETA BEFORE
b. BETA AFTER $>$ BETA BEFORE
c. BETA_AFTER $=$ BETA_BEFORE

Table 2 : Wilcoxon signed-rank test Statistics

\begin{tabular}{|l|r|}
\hline & BETA AFTER - BETA BEFORE \\
\hline Z & $-1.020^{\mathrm{b}}$ \\
Asymp. Sig. (2-tailed) & .308 \\
\hline
\end{tabular}

a. Wilcoxon Signed Ranks Test

b. Based on positive ranks.

Table 3 : Beta before and after COVID-19

\begin{tabular}{|l|c|c|c|c|}
\multicolumn{1}{|c|}{ company } & $\begin{array}{c}\text { Company } \\
\text { code }\end{array}$ & $\begin{array}{c}\text { Beta before } \\
\text { COVID-19 }\end{array}$ & $\begin{array}{c}\text { Beta after } \\
\text { COVID-19 }\end{array}$ & $\begin{array}{c}\text { Change in } \\
\text { Beta }\end{array}$ \\
\hline Palestine Development \& Investment & PADICO.D & 1.057953429 & 1.104729831 & +0.046776 \\
\hline $\begin{array}{l}\text { Arab Palestinian Investment Company } \\
\text { APIC) }\end{array}$ & APIC.D & 0.479816132 & 0.069834139 & -0.409982 \\
\hline The National Bank & TNB & 5.704578486 & 0.575060363 & -5.1295181 \\
\hline Bank of Palestine & BOP.D & 0.53457372 & 1.007479341 & +0.472721 \\
\hline Ahleia Insurance Group & AIG.D & 1.241607457 & 0.212092327 & -1.0295151 \\
\hline Palestine Electric & PEC.D & 0.745498062 & 0.431826351 & -0.3136717 \\
\hline Palestine Telecommunications & PALTEL & 0.535328409 & 1.164132627 & +0.628807 \\
\hline Watania Mobile & OOREDOO & 1.488448118 & 0.138882267 & --1.349565 \\
\hline The National Carton Industry & NCI & -0.785374833 & -0.298686392 & +0.486688 \\
\hline Jerusalem Cigarette & JCC & 0.325649292 & -0.672164238 & -0.9978134 \\
\hline Jerusalem Pharmaceutical & JPH.D & -0.225632076 & 0.079384952 & +0.305016 \\
\hline Birzeit Pharmaceuticals & BPC.D & -0.108898886 & -0.111485298 & -0.0025864 \\
\hline
\end{tabular}

\section{Conclusion.}

The study examines the ability of beta factor to reflect the systematic risks resulted from the COVID-19 crisis and 
examines the impact of COVID-19 crisis on stock returns in Palestine Stock Exchange, Stock beta factors has been calculated before and after the official announcement of the first confirmed case of COVID-19 by the Palestinian Ministry of Health.

The result showed short-term downturn in stock market returns, and that there is significant effect of Covid19 on the Palestine Stock Exchange.

The study has suggested that the people of Palestine absorb instability and uncertainty quickly . The people react for short period of time and after that they absorb the noisy information. In other word, uncertainty has become certain in peoples life (Qubbaja and Abu Omar,2019). This result also consistent with studies that proved Indian stock markets became more information inefficient after the coronavirus outbreak (Okorie and Lin.2021), and with study which found COVID-19 crisis does not affect stock returns for the portfolios consisting of stocks with high and medium B/M ratio and the portfolios consisting of small stocks. .( Abd-Alla, 2020)

Future research should investigate the longer-term impact of the pandemic on systematic risks measured by beta in Palestine Stock Exchange. It is suggested to conduct comparative studies by taking more global samples.

\section{References}

- Abd-Alla, Mostafa Hussein.(2020) COVID-19 crisis as a systematic risk: an empirical study in the egyptian stock market, Journal of Financial Studies, 2020, vol. 5, issue 9, 86-100.

- $\quad$ Adnan Qubbaja \& Subhi Abu Omar, 2019. "The Impact of Political Events on Palestine Securities Exchange Returns: An Empirical Study between (1997-2016)," International Journal of Academic Research in Accounting, Finance and Management Sciences, vol. 9(3), pages 287-294, July.

- $\quad$ Alkhatib, A., \& Harahsheh, M. (2014). Market Efficiency: The Case Of Palestine Exchange (Pex). World Journal Of Social Sciences, 4(1), Pp. 196-206.

- Ashraf, B. N. (2020). Stock markets' reaction to COVID-19: Cases or fatalities?. Research in International Business and Finance, 54, 101249. https://doi.org/10.1016/j.ribaf.2020.101249

- $\quad$ Aslam, F., Mohmand, Y. T., Ferreira, P., Memon, B. A., Khan, M., \& Khan, M. (2020). Network analysis of global stock markets at the beginning of the coronavirus disease (Covid-19) outbreak. Borsa Istanbul Review. 20(S1), S49-S61. https:org/10.1016/j.bir.2020.09.003

- $\quad$ Bash, A. (2020). International Evidence of Covid-19 and Stock Market Returns: An Event Study Analysis. International Journal of Economics and Financial Issues, 10(4), 34-38.

- $\quad$ Cao, W., Fang, Z., Hou, G., Han, M., Xu, X., Dong, J., \& Zheng, J. (2020). The psychological impact of the COVID-19 epidemic on college students in China. Psychiatry Research, 287, 112934.

- $\quad$ CFA. (2020). Stocks Turned Upside Down? The COVID-19 Beta Effect

- $\quad$ Evangelos, V.( 2021) Efficient markets hypothesis in the time of covid-19, Review of Economic Analysis ; 13(1):45-63, 2021.

- International Labour Organization.( 2020) . Impact of COVID-19 on the Palestinian labour market - A forecasting model analysis

- Khanthavit, A. (2020). Measuring COVID-19 Effects on World and National Stock Market Returns. Journal of Asian Finance, Economics and Business 8(2), 1-13.

- Kulal, A. (2020). Impact of coronavirus on indian stock market-an event study with reference to nifty 50. SSRN Electronic Journal. https://doi.org/10.2139/ssrn.3768419

- $\quad$ Liu, H., Manzoor, A., Wang, C., Zhang, L., \& Manzoor, Z. (2020). The COVID-19 outbreak and affected countries stock markets response. International Journal of Environmental Research and Public Health, 17(8), 2800

- $\quad$ Okorie, D. I., \& Lin, B. (2021). Stock markets and the COVID-19 fractal contagion effects. Finance Research Letters, 38, 101640. https://doi.org/10.1016/j.frl.2020.101640

- $\quad$ Rahman, M. L., Amin, A., \& Al Mamun, M. A. (2021). The COVID-19 outbreak and stock market reactions: Evidence from Australia. Finance Research Letters, 38, 101832. https:/doi.org/10.1016/j.frl.2020.101832

- Sharma, S. S. (2020). A note on the Asian market volatility during the COVID-19 pandemic. Asian Economics Letters, 1(2), 17661. https://doi.org/10.46557/001c.17661

- Yousef, I. (2020): The Impact of Coronavirus on Stock Market Volatility. International Journal of Psychosocial Rehabilitation, Vol. 24, Issue 06, 2020 ISSN: 1475-7192 